\title{
THE EFFECTS OF THIOCYANATE ON BASAL AND SUPPLEMENTAL BLOOD PRESSURES
}

\author{
BY \\ K. SEVERIN ALSTAD
}

From the Department of Medicine, University of Otago, New Zealand

Received January 21, 1949

Despite the many conflicting reports published regarding the effect of thiocyanate on high blood pressure it has been shown (Alstad, 1948) that there were indications that in certain patients high blood pressure may be reduced by such treatment. Allusion was made to the impression that the fall was due to a reduction in both the basal and the supplemental pressure, taking basal to mean the pressure recorded after the removal of certain stimuli both intrinsic and extrinsic, and supplemental to refer to the part of the casual blood pressure that reflects the physical, emotional, and metabolic activity of the patient at the time (Alam et al., 1943).

Thirty-two patients, selected because of a certain degree of hypertension, were investigated and were treated with potassium thiocyanate in doses varying from 0.3 to $0.9 \mathrm{~g}$. daily, most of them for over nine months. The average age of the group was 56 years, twenty being over 50 years, and eight over 60 years of age. Females predominated over males, the ratio being 21 of the former to 11 of the latter. No patient was rejected because of complications of hypertension such as encephalopathy, angina pectoris, or previous cardiac failure. The casual pressures were recorded in a separate examination room after the patient had been recumbent for a few minutes; basal blood pressures were taken in hospital after a night's rest assured by hypnotics, as described by Kilpatrick (1948). During treatment blood was removed weekly for serum thiocyanate estimation until a desired level was obtained, thereafter the estimations were carried out at longer intervals.

The dose of a therapeutic agent varies from patient to patient and in such an investigation as this the drug must be used in an effective amount; hence the difficulty of determining a control series exactly comparable. To overcome this it was decided to attempt to control the patients against themselves, achieving this by replacing the drug with a placebo similar in appearance and in taste but containing no thiocyanate. This was done only after a significant fall in blood pressure had occurred, or after the patient had been treated for at least three months, that is, at a time when such a fall might have been expected. Care was taken to continue the routine of examination and blood sampling in a manner exactly comparable to that adopted when thiocyanate was being given. It was possible to arrange this control in 27 patients, the remaining 5 being omitted because of discontinuance of treatment due to change of location or of some complication of therapy. The results are shown in Table I.

\section{Basal Blood Pressure Reduction}

The basal blood pressure, being recorded under conditions calculated to remove the effect of intrinsic and extrinsic stimuli, is probably a very reliable measure of the minimum pressure to which the cardiovascular system is subjected. It indicates the level to which the casual pressure may fall and is the guide to the fixity or lability of the hypertension according as the difference between it and the casual pressure is small or great. In the 32 patients examined an interesting relationship exists between the basal and casual pressures as shown in Fig. 1. Those patients with high casual pressure tend to have associated high basal pressure, indicating that an increase in the basal pressure is responsible, in part at least, for the high casual pressure in hypertensives.

Reduction of the basal blood pressure in any way, if produced by simple methods, would be of considerable importance to hypertensive patients. It is known that this may be effected by sympathectomy though not necessarily permanently. That a reduction may be produced in some cases by thiocyanate is seen from the fact that in 20 patients or 62 per cent, a fall in basal pressure of greater 


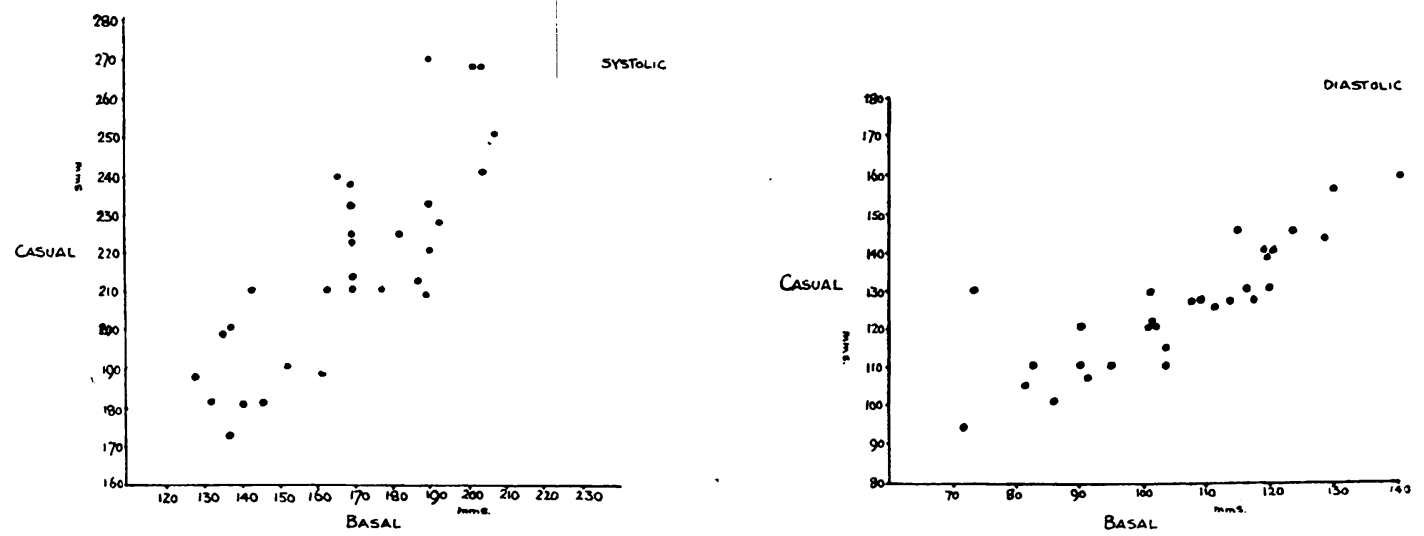

FIG. 1.-Relationship of initial basal pressure to initial casual pressure.

TABLE I

Reduction of Blood Pressure in Thirty-two Patients Treated with Potassium Thiocyanate and with a Placebo

\begin{tabular}{|c|c|c|c|c|c|c|c|c|c|}
\hline \multirow{2}{*}{$\begin{array}{l}\text { Case } \\
\text { No. }\end{array}$} & \multicolumn{3}{|c|}{ Initial pressure } & \multicolumn{3}{|c|}{ Reduction with treatment } & \multicolumn{3}{|c|}{ Reduction with placebo } \\
\hline & $\begin{array}{c}\text { Casual } \\
\text { (CI) }\end{array}$ & $\begin{array}{c}\text { Basal } \\
\text { (BI) }\end{array}$ & $\begin{array}{l}\text { Supple- } \\
\text { mental } \\
\text { (SI) }\end{array}$ & $\begin{array}{c}\text { Casual } \\
\text { (CI-CT) }\end{array}$ & $\begin{array}{c}\text { Basal } \\
\text { (BI-BT) }\end{array}$ & $\begin{array}{l}\text { Supple- } \\
\text { mental } \\
\text { (SI-ST) }\end{array}$ & $\begin{array}{l}\text { Casual } \\
\text { (CI-CP) }\end{array}$ & $\begin{array}{c}\text { Basal } \\
\text { (BI-BP) }\end{array}$ & $\begin{array}{l}\text { Supple- } \\
\text { mental } \\
\text { (SI-SP) }\end{array}$ \\
\hline $\begin{array}{r}1 \\
2 \\
3 \\
4 \\
5 \\
6 \\
7 \\
8 \\
9 \\
10 \\
11 \\
12 \\
13 \\
14 \\
15 \\
16 \\
17 \\
18 \\
19 \\
20 \\
21 \\
22 \\
23 \\
24 \\
25 \\
26 \\
27 \\
28 \\
29 \\
30 \\
31 \\
32\end{array}$ & $\begin{array}{l}190 / 110 \\
215 / 135 \\
184 / 104 \\
232 / 128 \\
228 / 132 \\
230 / 120 \\
180 / 110 \\
240 / 124 \\
188 / 108 \\
213 / 130 \\
210 / 140 \\
225 / 163 \\
254 / 140 \\
235 / 140 \\
230 / 130 \\
241 / 137 \\
170 / 131 \\
185 / 110 \\
193 / 128 \\
185 / 120 \\
211 / 123 \\
200 / 95 \\
200 / 120 \\
239 / 125 \\
275 / 146 \\
220 / 120 \\
231 / 130 \\
242 / 121 \\
209 / 120 \\
234 / 117 \\
263 / 145 \\
265 / 161\end{array}$ & $\begin{array}{l}128 / 84 \\
170 / 116 \\
132 / 82 \\
170 / 106 \\
170 / 108 \\
172 / 102 \\
142 / 94 \\
210 / 112 \\
160 / 90 \\
142 / 74 \\
176 / 122 \\
183 / 131 \\
204 / 120 \\
190 / / 20 \\
168 / 120 \\
163 / 85 \\
137 / 100 \\
141 / 92 \\
153 / 114 \\
145 / 102 \\
163 / 102 \\
136 / 73 \\
136 / 90 \\
171 / 107 \\
186 / 114 \\
192 / 106 \\
193 / 115 \\
227 / 125 \\
185 / 115 \\
189 / 104 \\
217 / 127 \\
199 / 140\end{array}$ & $\begin{array}{l}62 / 26 \\
45 / 19 \\
52 / 22 \\
62 / 22 \\
58 / 24 \\
58 / 18 \\
38 / 16 \\
30 / 12 \\
28 / 18 \\
71 / 56 \\
34 / 18 \\
42 / 32 \\
50 / 20 \\
452 / 20 \\
62 / 10 \\
78 / 52 \\
33 / 31 \\
44 / 18 \\
40 / 14 \\
40 / 18 \\
48 / 21 \\
64 / 22 \\
64 / 30 \\
68 / 18 \\
89 / 32 \\
28 / 14 \\
38 / 15 \\
15 / 0 \\
24 / 5 \\
45 / 13 \\
46 / 18 \\
66 / 21\end{array}$ & $\begin{array}{l}65 / 30 \\
47 / 22 \\
64 / 24 \\
52 / 20 \\
60 / 32 \\
40 / 20 \\
40 / 22 \\
65 / 24 \\
44 / 20 \\
63 / 40 \\
40 / 30 \\
35 / 33 \\
44 / 30 \\
45 / 20 \\
70 / 40 \\
42 / 37 \\
41 / 43 \\
41 / 20 \\
33 / 18 \\
35 / 20 \\
30 / 23 \\
32 / 20 \\
40 / 20 \\
29 / 22 \\
35 / 10 \\
30 / 10 \\
20 / 10 \\
21 / 9 \\
20 / 10 \\
24 / 16 \\
30 / 15 \\
9 / 10\end{array}$ & $\begin{array}{c}40 / 32 \\
30 / 16 \\
36 / 18 \\
24 / 10 \\
38 / 30 \\
30 / 18 \\
20 / 20 \\
28 / 12 \\
30 / 16 \\
22 / 14 \\
28 / 10 \\
47 / 39 \\
18 / 18 \\
44 / 18 \\
36 / 30 \\
41 / 13 \\
15 / 12 \\
25 / 10 \\
17 / 12 \\
15 / 12 \\
11 / 2 \\
0 / 7 \\
0 / 0 \\
17 / 5 \\
14 / 12 \\
18 / 2 \\
0 / 0 \\
0 / 3 \\
8 / 0 \\
16 / 5 \\
13 / 23 \\
14 / 12\end{array}$ & $\begin{array}{l}25 / 0 \\
15 / 11 \\
28 / 6 \\
28 / 20 \\
12 / 2 \\
10 / 2 \\
20 / 2 \\
30 / 12 \\
14 / 4 \\
41 / 26 \\
12 / 18 \\
0 / 0 \\
26 / 12 \\
1 / 2 \\
34 / 10 \\
1 / 24 \\
26 / 31 \\
16 / 0 \\
16 / 6 \\
20 / 8 \\
20 / 22 \\
36 / 14 \\
40 / 20 \\
12 / 10 \\
12 / 8 \\
12 / 14 \\
23 / 14 \\
0 / 0 \\
2 / 6 \\
18 / 0 \\
14 / 0 \\
0 / 0\end{array}$ & $\begin{array}{l}20 / 0 \\
15 / 15 \\
34 / 4 \\
32 / 16 \\
18 / 12 \\
10 / 10 \\
30 / 16 \\
18 / 4 \\
18 / 0 \\
43 / 40 \\
10 / 10 \\
14 / 19 \\
22 / 10 \\
5 / 8 \\
36 / 10 \\
7 / 15 \\
20 / 36 \\
20 / 0 \\
13 / 10 \\
15 / 10 \\
0 / 4 \\
20 / 4 \\
30 / 10 \\
9 / 12 \\
9 / 6 \\
10 / 0 \\
10 / 10 \\
= \\
= \\
= \\
-\end{array}$ & $\begin{array}{c}+6 / 0 \\
12 / 4 \\
18 / 8 \\
+4 /+10 \\
12 / 4 \\
+4 /+4 \\
6 / 6 \\
0 /+6 \\
4 /+2 \\
8 / 2 \\
+4 /+6 \\
4 / 0 \\
+6 / 0 \\
6 / 0 \\
14 / 0 \\
5 /+5 \\
+3 / 6 \\
1 / 6 \\
+3 /+2 \\
4 / 2 \\
2 / 0 \\
0 / 7 \\
+4 /+4 \\
3 / 3 \\
0 / 0 \\
2 / 0 \\
0 / 2 \\
= \\
= \\
= \\
-\end{array}$ & $\begin{array}{c}26 / 0 \\
3 / 11 \\
16 /+4 \\
36 / 22 \\
6 / 8 \\
14 / 14 \\
24 / 10 \\
28 / 10 \\
14 / 2 \\
35 / 38 \\
14 / 16 \\
8 / 17 \\
28 / 10 \\
+1 / 8 \\
12 / 10 \\
2 / 20 \\
23 / 30 \\
19 /+6 \\
16 / 12 \\
11 / 8 \\
0 / 1 \\
25 / 10 \\
34 / 14 \\
8 / 8 \\
8 / 8 \\
8 / 2 \\
13 / 8 \\
= \\
= \\
= \\
-\end{array}$ \\
\hline
\end{tabular}



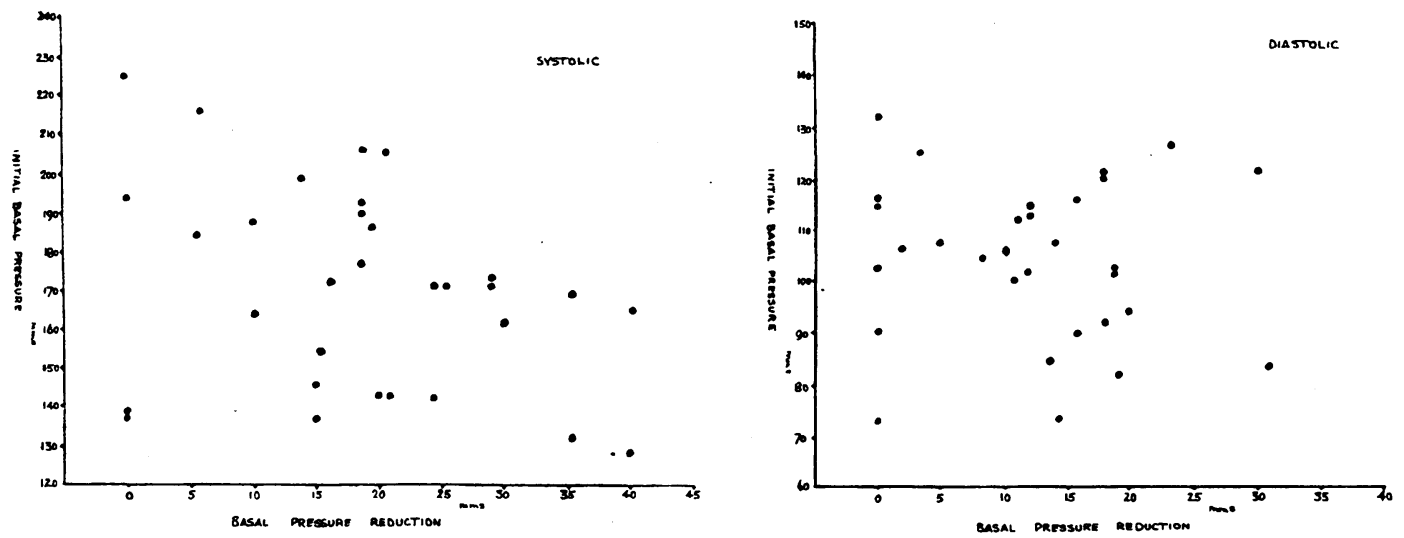

FIG. 2.-Relationship of basal pressure reduction to initial basal pressure.

than $15 / 10 \mathrm{~mm}$. was produced. In 12 of these the reduction was greater than $25 / 15 \mathrm{~mm}$. Falls in basal pressure less than $15 / 10 \mathrm{~mm}$. were disregarded, for although work in this department has shown the basal blood pressure to be a physiological constant in normal individuals and in hypertensives to be much less variable than the casual pressure, it was felt that variations less than $15 / 10 \mathrm{~mm}$. might come within the possible range of hypertensive fluctuation. The average fall was $25 \cdot 8 / 15 \cdot 7 \mathrm{~mm}$. in the 20 cases mentioned while in the remaining 12 the average fall was $10 / 6 \mathrm{~mm}$. If the fall in basal pressure is correlated with the initial basal blood pressure as in Fig. 2 there is an indication that the greater reductions tend to occur in patients with lower and moderate basal pressures. This tendency might be expected for one would anticipate high basal pressures in those with fixed hypertension and with more advanced pathological changes, and this is what obtained in this series as will be shown in another section.

With the use of a placebo the results were uniform no matter the extent of the reduction; the basal recordings with a placebo were similar to those before treatment commenced (cf. Fig. 3A). That the lowered basal pressure during treatment returned to within a few millimetres of its former level is taken to mean that the drug alone must account for the reduction, else with a placebo the pressure would not have returned consistently to the previous level. Had the basal pressure under the influence of a placebo not come back to the initial level (as will be seen occurred with the supplemental pressure) influences other than thiocyanate might have been responsible for the fall. There were three instances in which the reduction of basal blood pressure was maintained or returned very slowly to former levels even after thiocyanate was withdrawn completely for periods of up to three months during which no other treatment was given. Apart from the possibility of the initial readings not being truly basal, a simple explanation seems to be that the effect of thiocyanate in these cases greatly outlasted its presence in the blood. This prolonged effect has been noted by other investigators (Kurtz et al., 1941; Fischman, 1948). Thiocyanate appears to act by altering some internal mechanism, an action usually operative during its administration only but which is sometimes protracted.

\section{Supplemental Blood Pressure}

The supplemental blood pressure may be regarded as an index of the effect of various extrinsic stimuli acting on the patient at the time of recording. This part of the casual pressure has been shown by Smirk (1944) to be a variable independent of the basal pressure and accountable in the hypertensive for about one half of the increase above normal of the casual pressure (Smirk, 1944). With the removal of the excitatory causes as in sleep or with the conditions under which the basal pressure is recorded the supplemental pressure will approximate to zero at which level the blood pressure would, of course, be basal. That the supplemental pressure of a group of hypertensives would fall with any treatment, medicinal or psychological, might be anticipated as affecting the physical and emotional reactions of the patient. In the patients under observation the average supplemental blood pressure was $48 / 22 \mathrm{~mm}$. or about the level already noted in studies on hypertensives conducted in this department (Kilpatrick, 1948). Under treatment the average supplemental pressure was reduced to $27 / 12 \mathrm{~mm}$. The fact that, in all patients who were given a placebo, the supplemental pressure with it 
A

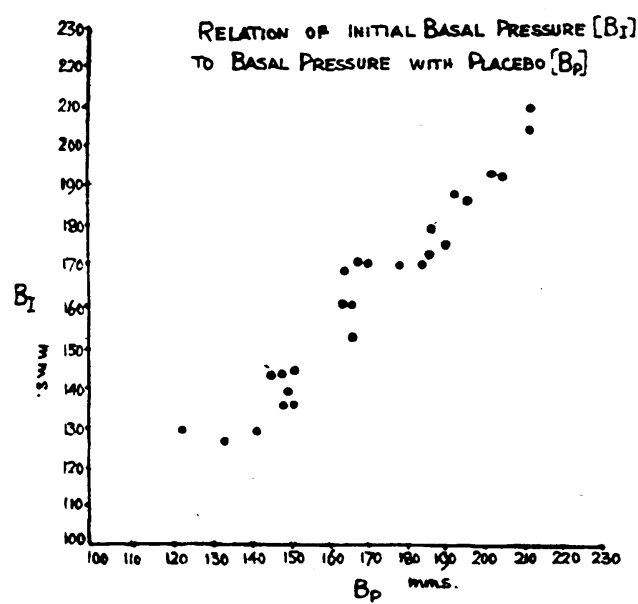

C

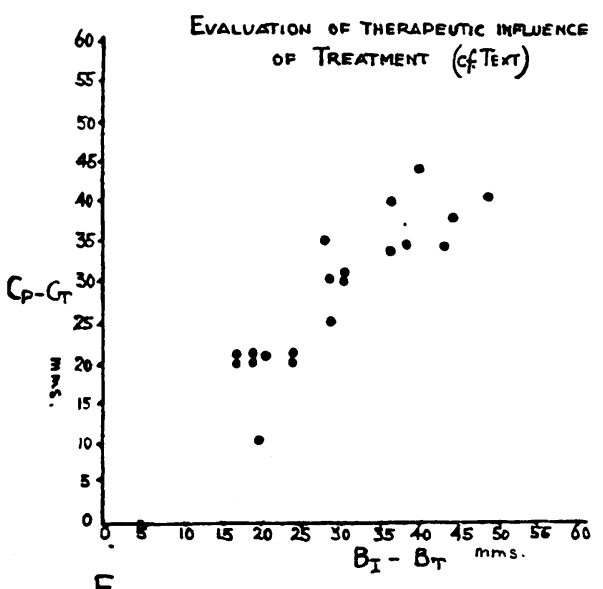

E

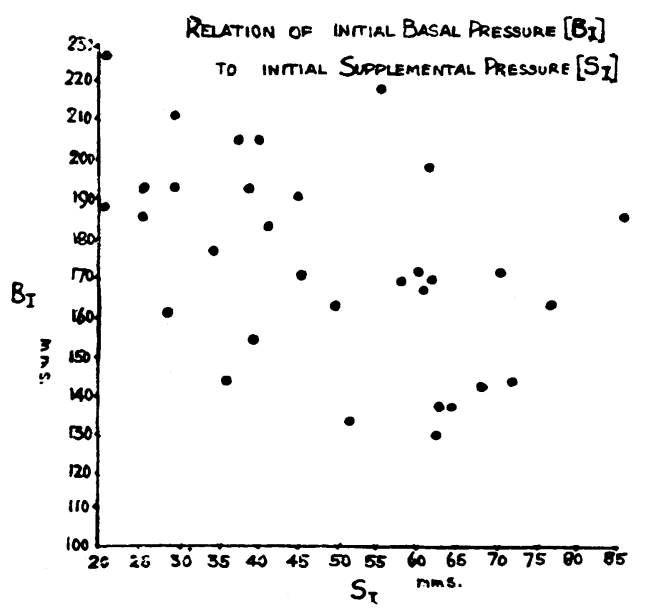

$B$

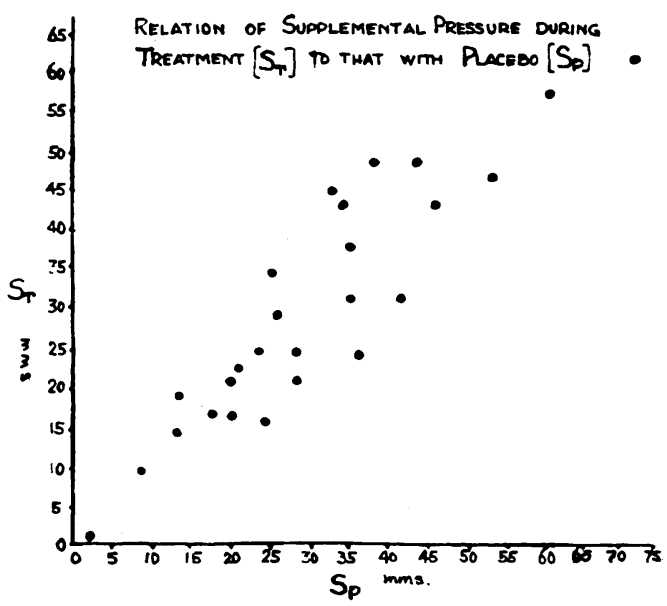

D

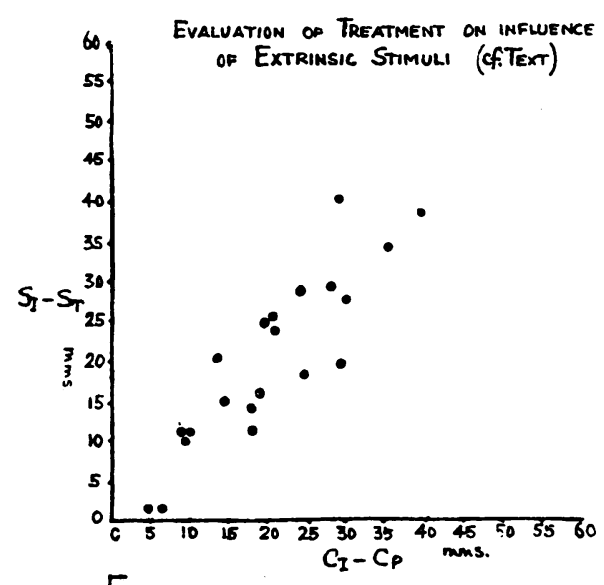

$\mathrm{F}$

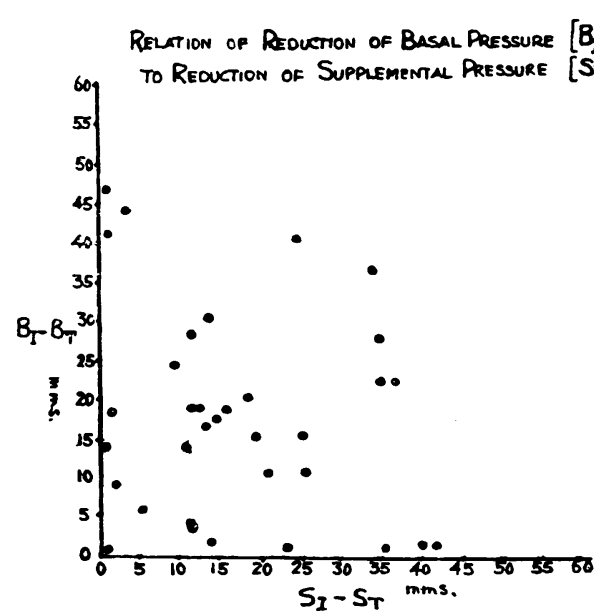

FIG. 3.-(A) Relation of initial basal pressure (BI) to basal pressure with placebo (BP).

(B) Relation of supplemental pressure during treatment (ST) to that with placebo (SP).

(C) Evaluation of therapeutic influence of treatment (of text).

(D) Evaluation of treatment on influence of extrinsic stimuli (of text).

(E) Relation of initial basal pressure (BI) to initial supplemental pressure (SI).

(F) Relation of reduction of basal pressure (BI-BT) to reduction of supplemental pressure (SI-ST). 
approximates to that during treatment (cf. Fig. 3B) indicates that the reduction affected in supplemental blood pressure is a psychological one, for one could not expect an alteration in the influence of emotional stimuli when the patient is unaware of any change in the regime or medicine. If the effect were otherwise the supplemental pressure would be greater with a placebo than with the use of thiocyanate. The supplemental pressure fall in those patients with no significant alteration in basal pressure represents the total effect of thiocyanate therapy and therefore is due only to the psychological effect of treatment. The psychological effect of thiocyanate therapy therefore may be estimated by the difference between the initial supplemental pressure (SI) and that with a placebo (SP). This measure of the influence of thiocyanate in the supplemental pressure as opposed to its effect on the basal pressure may be shown arithmetically to equal the difference between the initial casual pressure $(\mathrm{CI})$ and the casual pressure with a placebo (CP) since the casual pressure by definition is the sum of the basal and supplemental pressures, and as the basal pressure under treatment and with a placebo is the same. The relationship in this series between the differences of the initial casual and supplemental pressures and those with a placebo, CI-CP and SI-ST, respectively, is indicated in Fig. 3D in those patients whose reduction in pressure was significant, the formula CI-CP allowing of a more direct estimate of the psychological influences of treatment of patients in whom, for any reason basal recordings are unobtainable. Again as the supplemental pressure with thiocyanate and with a placebo have been shown to be approximately the same (cf. Fig. 3B) it follows (because the casual pressure is the sum of the basal and supplemental pressures) that the measurement of the direct effect of thiocyanate (BI-BT) will be the same as the difference between the casual under treatment and with a placebo $(\mathrm{CP}-\mathrm{CT})$ so allowing of a measurement of this influence without the necessity of having recordings of the basal blood pressure. That this relationship is present in this series is seen by scrutiny of Fig. 3C. These relationships are present only when there is a significant fall in pressure with treatment.

When the relationship of the initial basal and supplemental pressures is regarded (cf. Fig. 3E), it will be seen that there is a tendency for higher basal pressures to be associated with lower supplemental pressures, e.g. of 10 basal pressures over $180 \mathrm{~mm}$. 8 were associated with supplemental pressures less than $45 \mathrm{~mm}$., while of 18 under 180 only 6 had associated supplemental pressures less than $45 \mathrm{~mm}$. A possible explanation may lie in the fact that most of the patients whose basal blood pressure was over $180 \mathrm{~mm}$. were those in whom pathological changes were more advanced and therefore the cardiovascular system would be less able to reflect the effects of extrinsic stimuli. Smirk (1944) found the basal and supplemental pressures were substantially independent variables in a group of patients with essential hypertension selected for the absence of congestive heart failure and other complications. Kilpatrick (1948) showed that when heart failure occurred the supplemental pressure was reduced in greater degree relative to the basal. It is not surprising, therefore, that in the present series of cases including both groups that some of the more advanced hypertensives with heart failure or impending failure have lower supplemental pressures.

It would be likely, as the effect of thiocyanate on the supplemental pressure is independent of the effect on the basal that the reduction effected in the former would bear no relation to that produced in the latter; this is indicated in Fig. 3F which shows the basal pressure reduction plotted against the fall in supplemental pressure.

It would appear, therefore, that the effect of thiocyanate therapy on hypertensives in reducing blood pressure is a direct one as measured by the fall in basal pressure and also an indirect one as measured by the reduction in supplemental pressure, the combination of influences being responsible for the alteration produced in the casual blood pressure.

At this juncture one may conveniently regard the blood pressure reductions in the light of the extent of pathological change evident in the patients examined. All the patients in this series showed evidence of pathological changes associated with hypertension, whatever the ætiology, and this may be because the average age was over 55 years. All patients except two had some degree of cardiac enlargement involving the left ventrical which was of the typical hypertensive shape; it was possible to classify the enlargement as minimal, moderate, and considerable. Electrocardiography showed left axis shift in all cases, with a varying degree of left ventricular strain in over 50 per cent, particularly in those with large hearts. As the retinal vessels are the only ones capable of direct examination it was largely on the basis of retinal vascular change that the following clinical classification of the patients depends. Four subdivisions seemed practicable namely:

Group 1. (a) Minimal retinal changes in the shape of tortuosity and mild arterial constriction. Slight or no cardiac enlargement. Left axis deviation.

Group 2. (b) Moderate retinal changes, tortuosity, vascular constriction and nipping of the 

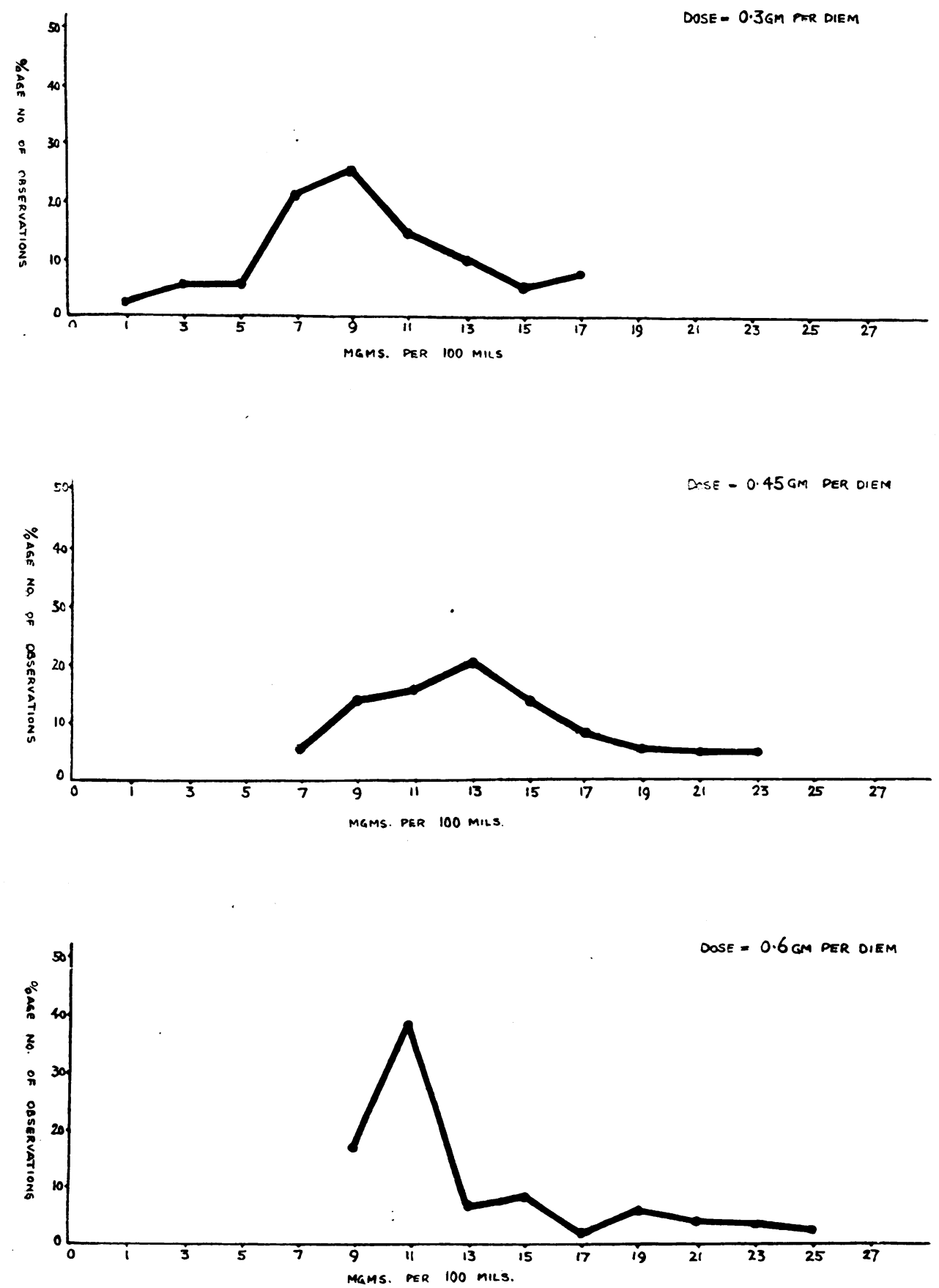

FIG. 4.-Relationship of thiocyanate serum-concentration to dosage. 
arteriovenous crossings. Moderate cardiac enlargement.

Group 3. (c) Marked retinal change but without papillœdema, hæmorrhage, or exudate. Cardiac enlargement usually moderate.

Group 4. (d) Marked retinal changes including hæmorrhage, exudate, and papillœdema. Cardiac enlargement usually considerable.

\section{TABLE II}

Relation of Reduction in Casual and in Basal Blood Pressure to Associated Vascular Change in PATIENTS WITH Hypertension

\begin{tabular}{c|c|c|c|c}
\hline $\begin{array}{c}\text { Clinical } \\
\text { sub- } \\
\text { division } \\
\text { (see text) }\end{array}$ & $\begin{array}{c}\text { Number } \\
\text { of } \\
\text { patients }\end{array}$ & $\begin{array}{c}\text { No. showing } \\
\text { reduction of } \\
\text { Casual pressure } \\
\text { 40/20 mm. }\end{array}$ & $\begin{array}{c}\text { No. showing re- } \\
\text { duction in Basal } \\
\text { pressure greater } \\
\text { than } \\
20 / 10 \\
\text { mm. }\end{array}$ & $\begin{array}{c}15 / 10 \\
\text { mm. }\end{array}$ \\
\hline Group 1 & 9 & 7 & 6 & 8 \\
\hline Group 2 & 3 & 2 & 1 & 2 \\
\hline Group 3 & 15 & 8 & 6 & 9 \\
\hline Group 4 & 5 & 1 & 1 & 1 \\
\hline Total .. & 32 & 18 & 14 & 20 \\
\hline
\end{tabular}

It will be seen from Table II that reductions in casual blood pressure occurred in each group, but the incidence of reduction was greater in groups 1 and 2 than in 2 and 3 . Indeed, out of 12 patients in the first two groups 9 had significant falls of casual pressure while in the latter two groups, 9 out of 20 patients showed any significant reduction in pressure. When the basal pressure reductions are viewed in the light of the degree of pathological change evident in the patients a similar distribution is seen. Thus it would appear that reductions in blood pressure tend to occur more easily in patients in whom the pathological changes associated with hypertension are least in evidence; such a conclusion is in keeping with the findings of Watkinson and Evans (1947) in this respect.

\section{Dosage and Blood Levels of KCNS}

The dosage of the drug was a variable conditioned mainly in these patients by the response in blood pressure reduction. Experience had already shown that to start at a high dosage was to invite the onset of complications particularly in the form of rashes and gastro-intestinal upset, hence the initial dose was the moderate one of $0 \cdot 3 \mathrm{~g}$. daily. Blood levels were recorded at weekly intervals using Bowler's modification of Barker's technique (1944). If the blood pressure response were inadequate after four weeks the dose was increased by $0.15 \mathrm{~g}$. daily. It was found that $0.45 \mathrm{~g}$. was the dose usually necessary to produce a reasonable fall in basal and in casual pressure. If, however, such a fall did not occur the dose was again increased, in several instances to $0.9 \mathrm{~g}$. daily. Generally the blood level followed the dose and larger doses were productive of higher serum concentrations (cf. Fig. 4). It was noted, that the lack of response in patients in whom no satisfactory fall of blood pressure was attained, could usually be attributed to the development of some complication of thiocyanate, e.g. rash or diarrhœa, early in treatment, in which case the drug was discontinued. Some patients did not have an appreciable fall in blood pressure despite large doses of drug and the attainment of high blood concentrations, e.g. over $20 \mathrm{mg}$. per $100 \mathrm{ml}$. Furthermore, in almost all patients in whom the pressure fall was adequate a dose of $0.45 \mathrm{~g}$. daily was sufficient and this generally produced blood levels in the region of 8-12 mg. per $100 \mathrm{ml}$. (cf. Fig. 4). It would seem, therefore, that an adequate blood level must be maintained in the region of $10 \mathrm{mg}$. per $100 \mathrm{ml}$., which is best produced slowly, and that if the patient does not show a fall in blood pressure when the level is raised to this extent they are most unlikely to do so by attempting to raise it still higher. In several instances blood levels of over $25 \mathrm{mg}$. per $100 \mathrm{ml}$. were maintained for several weeks without producing a further fall in blood pressure.

- Here one would remark that if a careful check is maintained on the serum level of thiocyanate and if the patient is seen frequently there appears to be little danger of untoward effects of therapy. Complications in this series were infrequent and took the form of rashes and gastro-intestinal upsets in four cases. In one only were mental symptoms encountered. As the average age in this series was 55 years it would indicate that age is no contraindication to therapy.

\section{Summary AND Conclusions}

Selected patients with hypertension have been treated with thiocyanate over periods varying from one to twenty months. A reduction in basal blood pressure of more than $15 / 10 \mathrm{~mm}$. was noted in twenty or 62 per cent of the patients. The greater reductions tended to occur with the lower or moderate blood pressures. This reduction in basal pressure has been shown to account for a proportion of the casual pressure fall and it has been suggested that the diminution in basal pressure represents the effective fall directly due to the therapy utilized, in this case, thiocyanate. 
Indications have been given that the effect of the psychological influence of thiocyanate treatment may be measured by taking the difference in casual blood pressure initially and that occurring with a placebo, or by subtracting the supplemental pressure under treatment from the initial supplemental pressure. This latter measure of the psychological influence of treatment depending on the conception that the supplemental pressure is an index of the effect of physical, metabolic, and emotional stimuli of which, under the conditions of this investigation, the emotion was the principal factor. In addition, the therapeutic effects of thiocyanate might be gauged either by taking the difference between the basal pressure before and during treatment or by the difference between the casual pressure under treatment and with a placebo. This was shown to be expressed conveniently by the equation $\mathrm{CI}-\mathrm{CP}$ $=\mathrm{BI}-\mathrm{BT}$ where $\mathrm{CI}$ and $\mathrm{CP}$ respectively were casual pressure initially and with a placebo, and BI and BT were the initial basal and the basal pressure under treatment.

It has been shown that greater reductions are to be anticipated in patients in whom permanent pathological changes secondary to the hypertension are not advanced. The more these changes are in evidence as judged by heart size, electrocardiogram, and fundal examination, the less likelihood is there of any influence occurring with thiocyanate.
The following conclusions can therefore be drawn from this study.

The influence of potassium thiocyanate in reducing significantly the casual blood pressure in selected patients with hypertension is due to a diminution in both basal and supplemental pressure.

The reduction in basal blood pressure probably represents the direct effect of thiocyanate on the cardiovascular system.

The reduction in supplemental blood pressure with thiocyanate is a measure of the influence of this treatment in diminishing the effect of extrinsic stimuli on the patient, and is produced in a manner similar to the effect of a placebo.

The larger reductions in basal blood pressure are found in patients in whom pathological changes in the cardiovascular system are not advanced.

The optimal serum concentration of potassium thiocyanate is $8-12 \mathrm{mg}$. per $100 \mathrm{ml}$. which may be attained usually by a dose of $0 \cdot 3-0.45 \mathrm{~g}$. daily. Toxic effects are commoner with levels above this limit, but with care the serum concentration may be raised to much higher levels without complications, although it is not considered advisable to produce blood serum levels above $12 \mathrm{mg}$. per $100 \mathrm{ml}$.

If the desired effect of thiocyanate therapy is not produced by serum concentrations of 8-12 mg. per $100 \mathrm{ml}$. it is unlikely to occur by increasing the dose and the blood level.

\section{REFERENCES}

Alam, G. H., Smirk, F. H., Gatman, M., and Nassif Amin. (1943). Brit. Heart J., 5, 160.

Alstad, K. S. (1948). Brit. med. J., 1, 250.

Bowler, R. G. (1944). Biochem. J., 38, 385.

Fischmann, E. J. (1948). Personal communication.

Kilpatrick, J. A. (1948). Brit. Heart J., 10, 48.
Kurtz, C. M., Shapiro, A. M., and Mills, C. S. (1941)• Amer. J. med. Sci., 202, 378.

Smirk, F. H. (1943). Brit. Heart J., 5, 156. (1944). Ibid., 6, 176.

Watkinson, G., and Evans, E. (1947). Brit. med. J., 1, 595. 